Ann. Biol. anim. Bioch. Biophys., 1978, 18 (2 B), 633-644.

\title{
Spermatogenesis and hydrolytic enzymes - A review
}

\author{
by T. VANHA-PERTTULA
}

Department of Anatomy, University of Kuopio, 70101 Kuopio 10, Finland.

Summary. Recent studies on specific hydrolytic enzymes of the testis have been reviewed. Special emphasis has been laid on their role in and association with the spermatogenic maturation. Many of these enzymes have been characterized as biochemically distinct from similar enzymes in other tissues. They can be utilized to reveal many special metabolic and physiologic features of the spermatogenic process.

\section{Introduction.}

Spermatogenesis is an orderly process of cell differentiation which leads to the formation of a highly specialized cell type, the spermatozoon. During this process the maturing cell maintains close contact with the Sertoli cells which appear to have a variety of functions during the differentiation process. Spermatogenic maturation is controlled by the testosterone production of interstitial Leydig cells as well as by pituitary FSH. These hormonal actions are presumably mediated preferentially via their effects on the Sertoli cells.

A number of lines of evidence indicate that cellular specialization during spermatogenesis is accompanied by molecular individualization. Sperm motility, for example, is dependent upon the formation of specialized contractile proteins, the nuclei of spermatozoa contain basic and acidic proteins which are typical of this cell type and special forms of enzymes have been characterized in the acrosomes of spermatozoa. Although the acrosome is regarded as a specialized lysosome, it also contains enzymes which differ from the lysosomal acid hydrolases in multiple physical and catalytic properties. Due to special physiological features, the cells undergoing spermatogenic maturation (spermatogonia, spermatocytes, spermatids) have been expected to provide useful biochemical correlations, « fingerprints », with well-established morphological criteria (Bishop, 1968). Although such a pattern has not yet been established in detail, many enzyme studies have offered new insight into the biochemical changes associated with meiosis, differentiation and maturation in the mammalian testis.

In the analysis of testicular enzymes a large variety of biochemical and histochemical methods have been utilized. Enzyme activities have been recorded in festes following treatments which alter the testicular function physiologically or pathologically. Interpretation of the biochemical data has generally been based on the relative 
proportions of various cell types existing in the testes at the time of sampling as well as on the normality of these cell types. For example, the loss of germinal cells would result in a change from a biochemical pattern reflecting normal germinal cells to that reflecting largely nongerminal Sertoli cells and interstitial Leydig cells. The biochemistry of nongerminal cells may, however, also be altered by nondestructive changes in the surviving cells themselves or by changes due to a loss of associated cells. Biochemical observations have not been and cannol always be correlated with histochemical methods, since the tissue preparation may influence the enzyme reaction, and enzyme solubility can cause a diffuse inaccurate histochemical reaction. In addition, biochemical and histochemical studies have commonly been carried out by use of separate substrates without careful correlation to the composite enzyme pattern with different substrate requirements, possibly present in the cells.

The analysis of specific proteins, viz. enzymes, has provided more detailed information regarding the formation of specific gene products within specific cell types on a temporal scale, and has defined several cellular responses to hormones at the molecular level. The experimental designs used to relate biochemical parameters to testicular cell types include a) testes taken during development from aspermatogenesis to complete spermatogenesis, b) tissues exhibiting degenerative changes in spermatogenesis, c) preparations from seminiferous tubular and interstitial tissues physically separated from each other, d) tubular sections separated according to the stage of the spermatogenic cycle, e) cellular elements from minced tubular preparations separated according to cell type, and combinations of the above. A number of recent studies on localization characteristics of selected hydrolytic enzymes in cells of testicular tubules are summarized as follows.

\section{Acrosomal enzymes.}

A large number of acrosomal enzymes have been characterized from sperm cells of different species. Table 1 gives a list of enzymes which have been dispersed from isolated acrosomes by treatment with detergents; they are hydrolytic enzymes with optimum activity mainly at acid $\mathrm{pH}$. Neutral and alkaline enzymes have also been isolated from the acrosomes. Only a few of these enzymes have been followed in the testis during spermatogenic maturation. Hyaluronidase is possibly an enzyme which

TABLE 1

Acrosomal enzymes of spermatozoa

Hyaluronidase Acid phosphatase $\beta$-galactosidase $\alpha$-mannosidase $\beta$-glucuronidase Neuraminidase Aryl sulfatase Phospholipase A
$N$-acetyl- $\beta$-glucosaminidase

Aspartyl amidase

Aryl amidase

Acid protease

Corona removing enzymes

Acrosin

RNAase

DNAase 
in the testis is only present in the acrosomes. Its activity is first defectable in the rat testis at 33 days of age (fig. 1) ; this coincides with the earliest appearance of the spermatids (Males and Turkington 1970). A rapid rise in specific activity during subsequent days correlates with the appearance of the proacrosomal cap in spermatids and with the development of this structure in the acrosome of the mature spermatozoon. Hyaluronidase activity, both in terms of total content and of specific activity, remains at a plateau once the full cycle of spermatogenesis has been completed. Hypophysectomy performed prior to the anticipated emergence of detectable hyaluronidase activity completely prevents the formation of spermatids and simultaneously the appearance of detectable hyaluronidase activity. Injections of LH and FSH or of testosterone are adequate stimuli to regain testicular hyaluronidase formation in the hypophysectomized rat. Genetic expression for hyaluronidase exibits a strict temporal pattern which may be termed a « biological clock ». Formation of the enzyme occurs precisely on days 33-34, and this time course cannot be accelerated by precocious or prepubertal treatments with gonadotropins or testosterone.

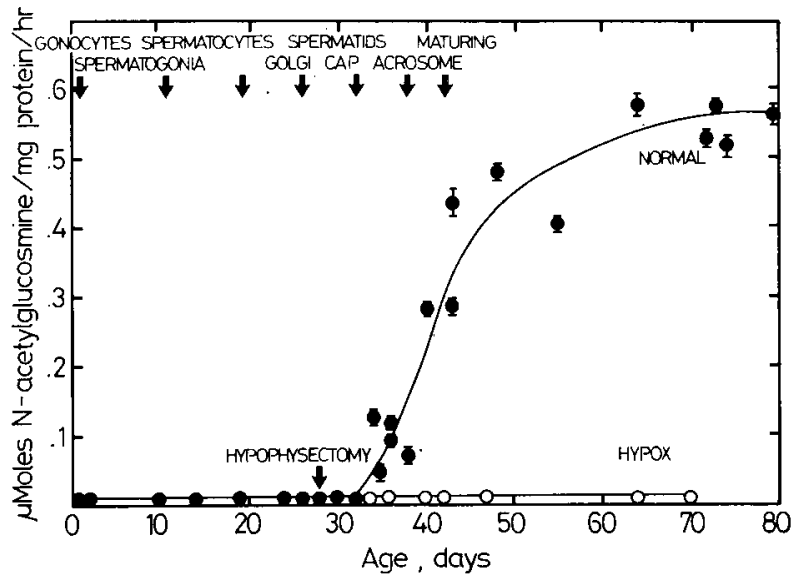

FIG. 1. - Testicular hyaluronidase during puberty of rat (•) as well as after hypophysectomy (o) (Reproduced from Males and Turkington, 1970).

Other acrosomal enzymes (table 1) presumably follow a similar pattern to various experimental procedures, but the multiplicity of isoenzymes in different cell components complicates the analysis of the biochemical data. Some of these enzymes are therefore described separately.

\section{$\beta$-Galactosidase.}

Chromatographic profiles of $\beta$-galactosidase have given two activity peaks with both testicular and sperm preparations (Majumber and Turkington 1974). The major sperm enzyme peak represents 90 p. 100 of the activity in this preparation and has an elution profile similar to the minor testicular enzyme which represents approximately 15 p. 100 of the testicular activity. Subcellular fractionation on discontinuous sucrose 
gradients has demonstrated that the major testicular enzyme is localized in the lysosomes, whereas the other isoenzyme exists solely in acrosomes.

During maturation acrosomal $\beta$-galactosidase appears only in spermatids and is incorporated into the proacrosome. It would be expected that during pubertal development total $\beta$-galactosidase activity would increase in the testis. However, due to the preponderance of the nonacrosomal enzyme in testicular tissue and its localization in nongerminal cells, the highest activity has been recorded in the newborn rat with an ensuing gradual decrease toward sexual maturity (fig. 2 ; Majumber ef al., 1975).

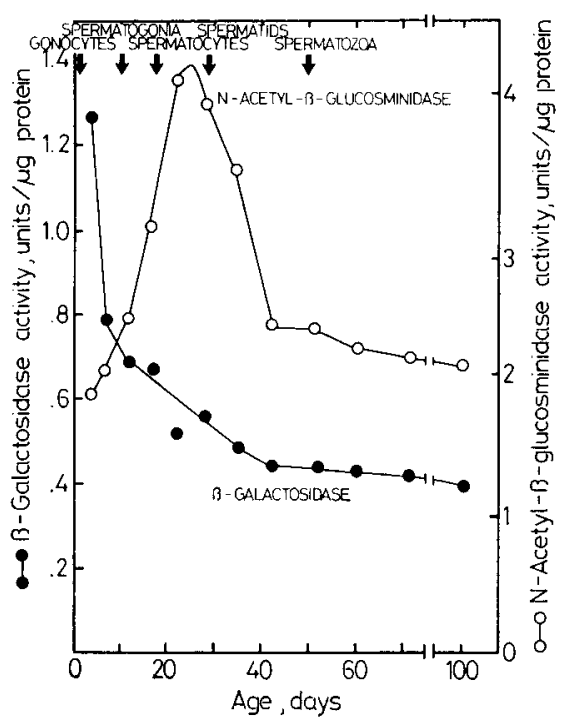

FIG. 2. - Testicular N-acefyl- $\beta$-glucosaminidase and $\beta$-galactosidase during puberty of rat (Reproduced from Majumber et al., 1975.)

\section{N-acetyl-p-glucosaminidase.}

A rather early increase of $\mathrm{N}$-acełyl- $\beta$-glucosaminidase in the rat testis is found during the formation of spermatogonia and spermatocytes (fig. 2 ; Majumber et al., 1975). Specific activity is maximal at approximately 25 days of age, but then declines rapidly with the subsequent formation of spermatids. Fractionation of rat testicular and sperm homogenates has resulted in three forms of the enzyme : testicular enzymes I and II as well as sperm enzyme III (Majumber and Turkington 1974). With cell fractionation, isoenzymes I and II have been localized to the lysosomes, and isoenzyme III to the acrosomal fraction of spermatozoa. All three isoenzymes are found in festicular tissue after the appearance of proacrosomal granules. The marked increase of enzymes I and II during early testicular development may be related to the maturation of the lysosomal system in the Sertoli and/or Leydig cells. The "dilution effect» of the spermatogenic cells lacking these enzymes I and II after meiosis may be responsible for the lower total enzyme activity. 


\section{Acid phosphatase.}

The situation of testicular acid phosphatase activity is still more complicated. Our own studies have shown that rat testicular tissue contains four different acid phosphatases (I-IV) with varying kinetic properties (fig. 3 ; Vanha-Perttula, 1971a, $b, c)$. Two of these enzymes (I and II) are mainly interstitial in location. Chromatographic fractionation of the isolated seminiferous fubules resulted in three activity peaks which co-eluted with enzymes II-IV. Acid phosphatases III and IV appear to be prevalent in the tubules. They are soluble and therefore the particulate enzyme II possibly represents both the acrosomal enzyme and the lysosomal activity of Sertoli cells. There appear to be few conventional lysosomes in spermatogenic cells.

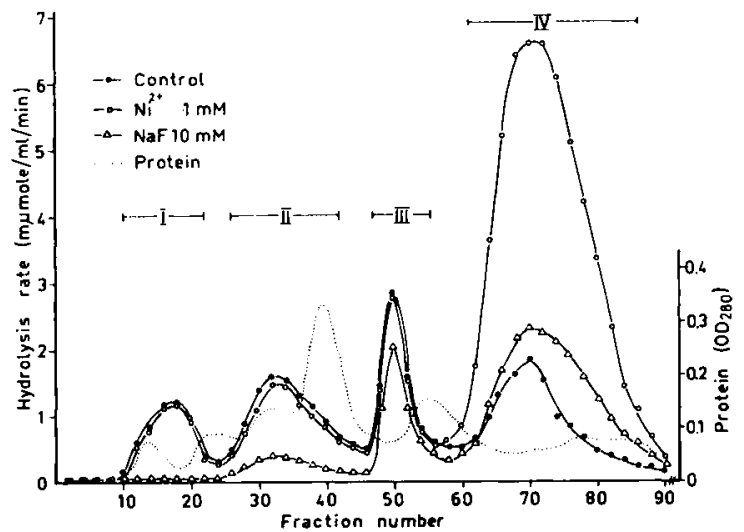

FIG. 3. - Hydrolysis of p-nitrophenyl phosphatase at pH 5.0 by DEAE-cellulose chromatogrophic froctions of rat testicular homogenate with and without some modifier substances (Reproduced from VanhaPerttula, 1971a).

Comparison of testicular acid phosphatases showed that enzymes I and II were sensitive to fluoride and tartrate, whereas enzymes III and IV were resistant. On the other hand, these two enzymes were more sensitive to heavy metal ions ( $\mathrm{Cu}^{2+}$, $\mathrm{Cd}^{2+}, \mathrm{Hg}^{2+}$ ) and the conventional fixatives (formaldehyde). A special property of enzyme IV was marked activation by some divalent metal ions, including $\mathrm{Co}, \mathrm{Zn}, \mathrm{Ni}$, $\mathrm{Mg}$, and $\mathrm{Mn}$ in decreasing order. Slight differences were also encountered in $\mathrm{pH}$ optima and $K_{m}$-values of these four enzymes.

With different assay systems these enzymes were separately quantified in different conditions (Vanha-Perttula and Nikkanen, 1973). It was found that the assays showing mainly enzyme I and II activities were rather constant during pubertal maturation. This indicates an even distribution of activities in Sertoli and Leydig cell lysosomes as well as in maturing acrosomes. Enzyme II showed a slight decline in activity as spermatids appeared; these seem to have a "diluting" effect on total enzyme activity.

The total activity of acid phosphatase with p-nitrophenyl phosphate as substrate increased slightly after $\mathbf{4 0}$ days of age during the final maturation stages of spermio- 
genesis (fig. 4). This elevating trend was detectable earlier when enzymes I and II were deleted from the reaction by fluoride inhibition. The contribution of enzyme IV could be clearly demonstrated by including cobalt in the incubation medium. A marked activation of the enzyme was then achieved with maximal levels at 50-60 days of age when the first spermatozoa are released. It is evident that this enzyme is closely associated with the final stages of spermatogenesis. After cryptorchidism and $\mathrm{CdCl}_{2}$ necrosis of spermatogenesis this enzyme was the most rapidly suppressed type of the testicular acid phosphatases. In contrast, after cryptorchidism the activity of enzyme I increased indicating a larger contribution of the interstitial cells of the remaining testicular cell population.

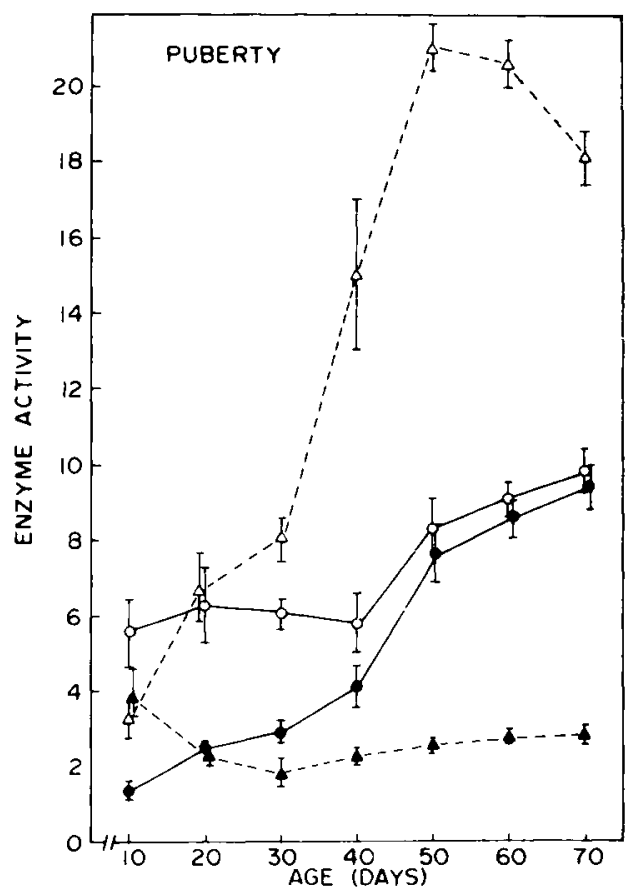

FIG. 4. - Acid phosphofose activity of rat testicular tissue during puberty with p-nitrophenyl phosphate (p-NPP) as substrate. o-o p-NPP; - p-NPP + NaF ; $\Delta--\Delta \mathrm{p}-\mathrm{NPP}+\mathrm{NaF}+\mathrm{Co}^{2+} ;--\Delta$ $\mathrm{P}-\mathrm{NPP}+\mathrm{Cu}^{2}+$ (Reproduced from Vanha-Perttula and Nikkanen, 1973.)

A further attempt to localize the soluble enzyme IV in the seminiferous tubules was carried out by analyzing enzyme activities from identified stages of the rat testicular seminiferous tubules (Parvinen and Vanha-Perttula, 1972). It was found that acid phosphatase IV showed the highest activity in stages VI-VII, corresponding to the final stages of spermatid maturation. Previous histochemical studies with the Gomori method have indicated that high acid phosphatase activity is found during these stages in the residual bodies (Niemi and Kormano, 1965). There were, however, no detailed studies on the properties of this enzyme activity. 
In many species (bull, ram) the residual bodies are transported with the spermatozoa into the epididymis and the ejaculate (Dott and Dingle, 1968). In rabbit epididymal content spermatozoa, residual bodies and cytoplasmic droplets have been shown to contain five acid phosphatases (Gonzales and Meizel 1973a, b). One of these is also $\mathrm{Zn}$-activated but differs from the corresponding testicular enzyme of the rat e.g. in substrate specificity. In many rodent species (guinea pig, hamster, mouse), the testicular acid phosphatases closely resemble the situation described in the rat (unpublished observation).

In rat the residual bodies presumably do not reach the epididymis, since analysis of the epididymal enzymes did not reveal such an activity (Nikkanen and VanhaPertfula, 1976). From these studies it can be concluded that acid phosphatase IV is a special testicular enzyme, which may participate in the destruction of the residual body. Close association of the late spermatid with an anchoring device to the Sertoli cell (Russell and Clermont 1976) could enhance the hydrolytic process by a possible transport of activating zinc ion to the site of the hydrolytic process.

The activity of acid phosphatase IV rapidly decreased after $\mathrm{CdCl}_{2}$-treatment which causes the destruction of the spermatogenic elements. The divalent metal ions which activate this enzyme are able to prevent necrosis. Also in vitro these ions prevent inhibition of the enzyme in a competitive manner (fig. 5). Since the blood-testis barrier is located in the intercellular tight junctions of the Sertoli cells (Dym and Fawcett, 1970), the effect of $\mathrm{Cd}^{2+}$ may initiate a pathological reaction in the spermatogenic cells by inhibiting this enzyme.

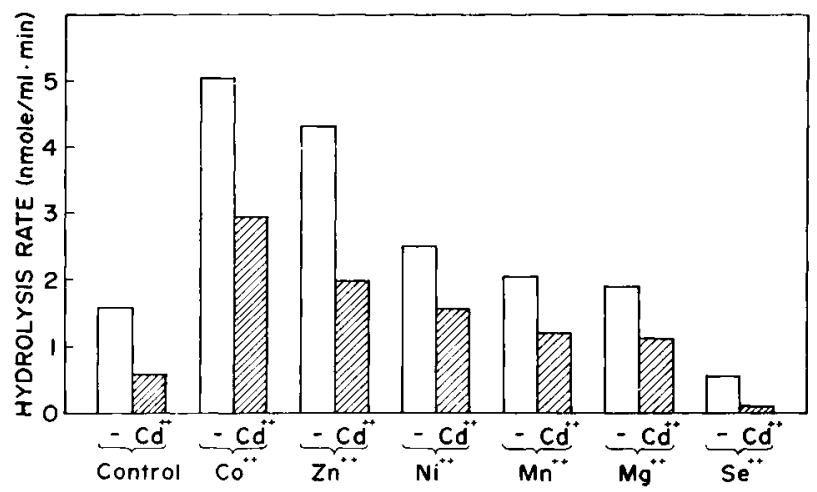

FIG. 5. - Inhibition by $C d^{2+}$ of testicular acid phosphatase IV with p-NPP as substrate and effect of addition of various divalent metal ions at equimolar concentrations ( $1 \mathrm{mmole} / 1$ ).

\section{Aminopeptidases.}

Four aminopeptidases have been separated by chromatographic fractionation from the rat testis (Vanha-Perttula, 1973a). Two of these enzymes (III-IV) are preferentially located in the tubules (fig. 6). Enzyme III hydrolyzes only basic amino acids from the $\mathrm{NH}_{2}$-terminus of peptides and proteins. This soluble enzyme most probably has an identical cellular site with the $\mathrm{Zn}$-activated acid phosphatase, since it also has 
the highest activity in stages VI-VII of the fubular spermatogenic wave (Parvinen and Vanha-Perttula, 1972).

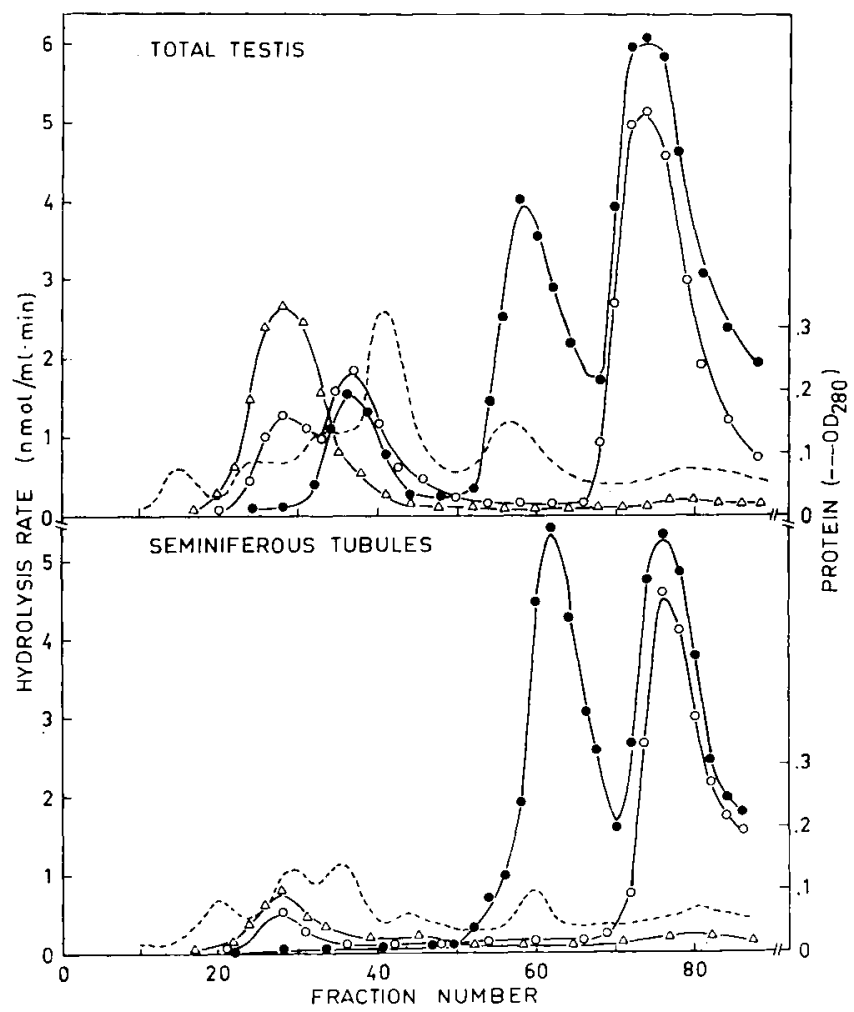

FIG. 6. - Hydrolysis of Leu- $\beta$-NA (0), Arg- $\beta$-NA (•) and Val- $\beta$-NA ( $\triangle$ ) by DEAE-cellulose chromatographic fractions of total and fubular homogenates of rat festis (Reproduced from Vanha-Perttula, 1973a).

During puberty, marked activation of this enzyme was observed, while cryptorchidism and $\mathrm{CdCl}_{2}$-treatment caused a rapid decline of activity simultaneously with depletion of the spermatids and spermatocytes from the spermatogenic epithelium (fig. 7, Vanha-Perttula, 1973b). It is concluded that this enzyme may be associated with the hydrolysis of basic protein components in the residual bodies. Labeling studies have shown that during replacement of the nuclear somatic histones with argininerich histones, lysine derivatives are transported to the residual body (Vaughn, 1966).

Aminopeptidase IV hydrolyzes a wide variefy of amino acid derivatives with cysteine activation. During puberty a gradual decline in activity was recorded, indicating a major contribution from nongerminal tubular elements and interstitial tissue (Vanha-Perttula, 1973b). Aminopeptidase l of the rat testis shows a substrate preference closely similar to that found in bull spermatozoa (Meizel and Cotham, 1972). The alterations of this enzyme activity in different physiological conditions, however, mostly appear to indicate the contribution of nongerminal elements of the testis.

Lysosomal dipeptidyl aminopeptidases have also been characterized by tissue 
fractionation of the rat testis (Vanha-Perttula, 1973c). One of these, hydrolyzing seryltyrosyl- $\beta$-naphthylamide at $\mathrm{pH} 4.5$ (cathepsin $C$ ), has a low activity in the seminiferous tubules, whereas the other enzyme, assayed with lysyl-alanyl- $\beta$-naphthylamide at $\mathrm{pH}$ 5.5, shows moderate activity in the tubules (Vanha-Pertfula, 1973c) as well as in isolated sperm cells (unpublished observation). During testicular maturation different patterns of these enzymes are recorded, which indicates an uneven distribution of the two lysosomal enzymes in different cell populations of the testis. Various responses are also recorded after cryptorchidism.

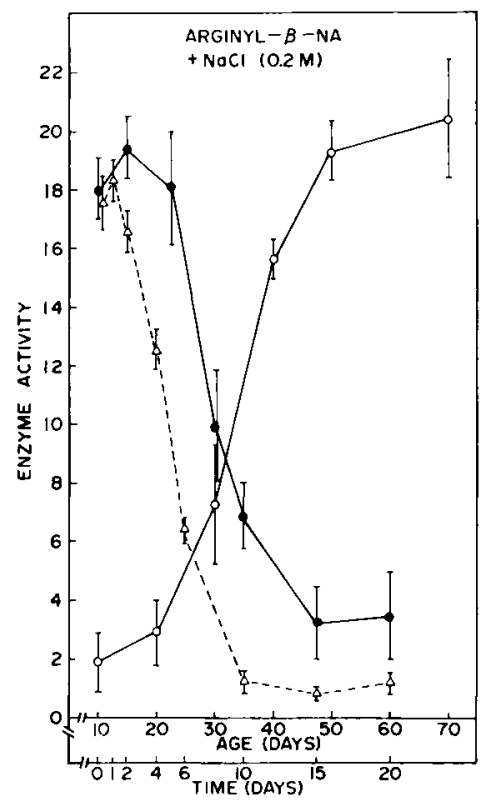

FIG. 7. - Hydrolysis of Arg- $\beta$-NA at pH 6,5 in the presence of $\mathrm{NaCl}(0.2$ mole/l) by rat testis during puberty $(\circ)$, after cryptorchidism $(\bullet)$ and after cadmium chloride treatment $(\Delta)$ (Reproduced from VanhaPerttula, 1973b).

\section{$\beta$-glucuronidase.}

$\beta$-glucuronidase has been histochemically localized in the Sertoli cells (Males and Turkington, 1971). The biochemical quantitation of this enzyme shows a fivefold decrease in specific activity as development progresses from the newborn stage to full maturity. The enzyme activity profile is not, however, identical with that reported for another marker enzyme of the Sertoli cells, gamma glutamyl-transpeptidase (Hodgen and Sherins, 1973). Further studies are therefore necessary to define the function of these two enzymes in testicular physiology.

\section{Nucleotide phosphohydrolases.}

The specific activities of two nonlysosomal enzymes, uridine diphosphatase and $5^{\prime}$-nucleotidase, have been followed during testicular maturation (Xuma and Turking- 
ton, 1972). Both enzymes show a low activity in the newborn rat testis, but with the formation of spermatogonia and spermatocytes their activities rise sharply to maximal levels at 26 days of age (fig. 8). After this, 5 '-nucleotidase remains constant during further spermatid maturation. In contrast, a sharp decline in UDPase levels was observed and a new plateau was reached with the achievement of steady-state spermatogenesis. $5^{\prime}$-nucleotidase has been cytochemically demonstrated in the cell membranes of all testicular cells, whereas UDPase is localized in the smooth endoplasmic reticulum of spermatocytes with a decrease in subsequent spermatogenic elements.

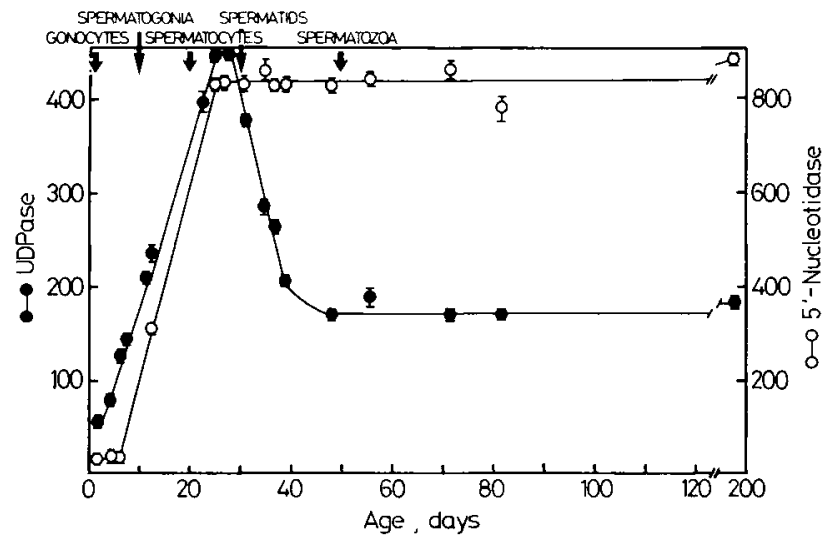

FIG. 8. - Testicular uridine diphosphatase (•) and $5^{\prime}$-nucleofidase $(0)$ during testicular maturation in rat (Reproduced from Xuma and Turkington, 1972).

Two types of cyclic nucleotide phosphodiesterases have been found in the rat testis (Monn et al., 1972). One of these (f-component) appears to be a specific spermatogenic « marker » in the testis. A rapid activation of this enzyme has been recorded between 20 and 50 days of age. The f-component first appears at 40 days of age, coincident with elongation of the spermatids, and increases to adult levels at 50 days of age.

Histochemical studies have shown different testicular cells and cell organelles active in the hydrolysis of nucleotide triphosphates. These may represent different enzyme species with variable cofactor requirements. Quantitatively a rise in the activity of (Ca-Mg)-adenosine triphosphatase has been recorded during pubertal maturation (Delhumeau-Ongay et al., 1973a) as well as after hypophysectomy and cryptorchidism (Delhumeau-Onday ef al., 1973b). The physiological interpretation of these findings still requires more detailed analysis.

\section{Conclusions.}

Studies of testicular enzymes have aimed at revealing specific marker enzymes for different cell components. Hydrolytic enzymes form only a small portion of the functionally active ingredients of this tissue, useful in the follow-up of physiological functions. The most interesting findings achieved in these studies are the description 
and characterization of testis-specific enzymes or isoenzymes. When such enzyme profiles can be completed for different cell types, a "fingerprinting " will be feasible for the whole tissue.

It is evident that hydrolytic enzymes of the testis show different profiles in response to physiological and pathological conditions affecting the tissue ; perhaps they cannot be induced by hormones as the secretory products of a cell may. These enzymes, however, depend on the integrity of the cell population, initially induced by hormonal stimuli, to complete a special sequence of maturation and specialization. The activation of the genetic machinery during the early stages of spermatogenesis forms the basis for the transcription and translation of unique proteins. These proteins are also immunologically different from the somatic constituents and should therefore be effectively guarded from immunologic attack and invasion by the lymphatic cells. The occluding junctions between adjacent Sertoli cells apparently form such an effective barrier which separates the adluminal compartment of the tubules with their specialized cell types and protein (enzyme) components.

Different activity patterns have also been reported for other groups of testicular enzymes (dehydrogenases, transferases, kinases). Among these, some specific tissue forms have been described which may also be more appropriate to special functions of the final product of the process - the spermatozoon. In some cases a large distribution of testis-specific enzymes (LDH-X, sorbitol dehydrogenase) in different species has been reported. Larger comparative studies with different hydrolytic enzymes have not been carried out, but preliminary observations indicate that interspecies differences prevail. These may include variations in the number of isoenzymes or variable substrate specificities or other kinetic properties.

27 e Congrès international des Sciences physiologiques, Symposium « Germ and somatic cell interaction 》 Paris, 21-23 juillet 1977.

Acknowledgments. - Aided by grants from The Sigrid Jusélius Foundation, Helsinki and The National Research Council for Medical Sciences, Finland.

Résumé. Les données récentes sur les hydrolases testiculaires sont passées en revue avec une attention particulière sur leur rôle dans, ou en rapport avec la maturation spermatique. Beaucoup de ces enzymes sont des entités biochimiques distinctes des enzymes similaires d'autres tissus. Elles peuvent être utilisées pour mettre en évidence beaucoup d'aspects physiologiques ou métaboliques spéciaux de la spermatogenèse.

\section{References}

BISHOP D. W., 1968. Testicular enzymes as fingerpints in the study of spermatogenesis, 261-286. In DIAMOND M., Reproduction and sexual behovior, Indiana Univ. Press, Ind.

DELHUMEAU-ONGAY G., TREJO-BAYONA R., LARA-VIVAS L., 1973a. Changes of $\left(\mathrm{Ca}^{2+} \mathrm{Mg}^{2+}\right)$ adenosine triphosphatase activity in rat testis throughout maturation. J. Reprod. Fert., 33, 513-517.

DELHUMEAU-ONGAY G., TREJO-BAYONA R., ALVAREZ R., LARA-VIVAS L., 1973b. Increase of $\left(\mathrm{Ca}^{2+}-\mathrm{Mg}^{2+}\right)$-adenosine triphosphatase activity in rat testis undergoing regression of the germinal epithelium. J. Reprod. Fert., 34, 149-153. 
DOTT H. M., DINGLE J. T., 1968. Distribution of lysosomal enzymes in the spermatozoa and cytoplasmic droplets of bull and ram. Exp. Cell Res., 52, 523-540.

DYM M., FAWCETT D. W., 1970. The blood-testis barrier in the rat and the physiological compartmentation of the seminiferous epithelium. Biol. Reprod., 3, 308-326.

GONZALES L. W., MEIZEL S., 1973a. Acid phosphatases of rabbit spermatozoa. I. Electrophoretic characterization of the multiple forms of acid phosphatase in rabbit spermatozoa and other semen constituents. Biochim. biophys. Acta, 320, 166-179.

GONZALES L. W., MEIZEL S., 1973b. Acid phosphatases of rabbit spermatozoa. II. Partial purification and biochemical characterization of the multiple forms of rabbit spermatozoan acid phosphatase. Biochim. biophys. Acta, 320, 180-194.

HODGEN G. D., SHERINS R. J., 1973. Enzymes as markers of testicular growth and development in the rat. Endocrinology, 93, 985-989.

MAJUMBER G. C., LESSIN S., TURKINGTON R. W., 1975. Hormonal regulation of isoenzymes of $\mathrm{N}$-acetyl- $\beta$-glucosaminidase and $\beta$-galactosidase during spermatogenesis in the rat. Endocrinology, 96, 890-897.

MAJUMBER G. C., TURKINGTON R. W., 1974. Acrosomal and lysosomal isoenzymes of $\beta$-galactosidase and $\mathrm{N}$-acetyl- $\beta$-glucosaminidase in rat testis. Biochemistry, 13, 2857-2864.

MALES J. L., TURKINGTON R. W., 1970. Hormonal regulation of hyaluronidase during spermatogenesis in the rat. J. biol. Chem., 245, 6329-6334.

MALES J. L., TURKINGTON R. W., 1971. Hormonal control of lysosomal enzymes during spermatogenesis in the rat. Endocrinology, 88, 579-588.

MEIZEL S., COTHAM J., 1972. Partial characterization of a new bull sperm arylamidase. J. Reprod. Fert., 28, 303-307.

MONN E., DESAUTEL M., CHRISTIANSEN R. O., 1972. Highly specific testicular adenosine 3', 5'-monophosphate phosphodiesterase associated with sexual maturation. Endocrinology, 91, 716-720.

NIEMI M., KORMANO M., 1965. Cyclical changes in and significance of lipids and acid phosphatase activity in the seminiferous fubules of the rat testis. Anat. Rec. 151, 159-170.

NIKKANEN V., VANHA-PERTTULA T., 1976. Acid phosphatases of the rat epididymis. I. Fractionation and substrate specificity. Andrologia, 8, 341-349.

PARVINEN M., VANHA-PERTTULA T., 1972. Identification and enzyme quantitation of the stages of the seminiferous epithelial wave in the rat. Anat. Rec., 174, 435-450.

RUSSELL L., CLERMONT Y., 1976. Anchoring device between Sertoli cells and late spermatids in rat seminiferous tubules. Anot. Rec., 185, 259-278.

VANHA-PERTTULA T., 1971a. A new type of acid phosphatase from rat testis. Experientia, 27, 42-44.

VANHA-PERTTULA T., 1971b. Subcellular distributions and properties of rat testicular acid phosphatases. Hisfochem. J., 3, 151-161.

VANHA-PERTTULA T., 1971c. Chromatographic fractionation and characterization of rat festicular acid phosphatases. Biochim. biophys. Acta, 227, 390-401.

VANHA-PERTTULA T., 1973a. Aminopeptidases of rat testis. I. Fractionation and characterization. J. Reprod. Fert. 32, 33-44.

VANHA-PERTTULA T., 1973b. Aminopeptidases of rat testis. II. Effects of puberty, cryptorchidism and cadmium chloride treatment. J. Reprod. Fert., 32, 45-53.

VANHA-PERTTULA T., 1973c. Aminopeptidases of rat testis. III. Activity of dipeptidyl aminopeptidases I and II in normal and experimental conditions. J. Reprod. Fert., 32, 55-63.

VANHA-PERTTULA T., NIKKANEN V., 1973. Acid phosphatases of the rat testis in experimental conditions. Acto endocr., 72, 376-390.

VAUGHN J. C., 1966. The relationship of the "sphere chromatophile " to the fate of displaced histones following histone transition in rat spermiogenesis. J. Cell Biol., 31, 257-278.

XUMA M., TURKINGTON R. W., 1972. Hormonal regulation of uridine diphosphatase during spermatogenesis in the rat. Endocrinology, 91, 415-522. 